\title{
Factors affecting the use and non-use of Learning Management Systems (LMS) by academic staff
}

\author{
Emma Coleman, Sive Mtshazi \\ University of the Witwatersrand, Johannesburg, South Africa
}

\begin{abstract}
The purpose of this research was to identify the factors that affect the use and non-use of a Learning Management System (LMS) by lecturers in a South African university. This research involved a qualitative case study of lecturers, and utilised questionnaires for data collection. Findings showed that both internal and external factors are important in shaping use of LMS. Contrary to the literature, high levels of use were found amongst the respondents with a high perception of ease of use and usefulness. However, due to issues such as lack of ongoing training, more advanced features of the technology were not being utilised. It also emerged that patterns of use were affected by pre-existing practices and that the perception of the system was affected by differences to the previous system. This study contributed to literature by providing in-depth analysis of why certain factors affect lectures' decision regarding LMS usage. Future research should consider the use of extended features of LMSs and the prior practices and systems used within the context of study to understand how they affect use or non-use of an LMS. This study contributes to practice through promoting understanding of why there is underuse of extended features of an LMS among lecturers.
\end{abstract}

Keywords: LMS, academic staff, use, adoption

Categories: • Applied computing $\sim$ Learning management systems

Email:

Emma Coleman emma.coleman@wits.ac.za (CORRESPONDING),

Article history:

Sive Mtshazi smtshazi@gmail.com

\section{INTRODUCTION}

Pressure from economic, social and technological forces drives tertiary institutions to implement systems that will accommodate the learning needs of students (Nanayakkara, 2007). According to Nanayakkara (2007), learning management systems (LMS) form part of the well-known e-delivery media in institutions today. "An LMS is a self-contained webpage with embedded instructional tools

Coleman, E. and Mtshazi, S. (2017). Factors affecting the use and non-use of Learning Management Systems (LMS) by academic staff. South African Computer Journal 29(3), 31-63. https://doi.org/10.18489/sacj.v29i3.459

Copyright (C) the author(s); published under a Creative Commons NonCommercial 4.0 License (CC BY-NC 4.0). This paper is (co-)authored by an associate editor of $S A C J$, Emma Coleman, and special precautions were taken to ensure anonymity of the review process. The author at no time had access to the decision process or the identity of the reviewers. $S A C J$ is a publication of the South African Institute of Computer Scientists and Information Technologists. ISSN 1015-7999 (print) ISSN 2313-7835 (online). 
that permit faculty to organise academic content and engage students in their learning" (Gautreau, 2011, p. 2).

LMS have a variety of benefits for lecturers. An LMS provides academic staff with continuous accessibility to perform their duties, centralised information about their students and interactive platforms that facilitate communication with students (Black, Beck, Dawson, Jinks, \& DiPietro, 2007). Moreover, integrating an LMS as an educational tool supports the preparation content of courses, reduces the planning time involved in a course delivery, and facilitates the administration of courses (Cabral, Pedro, \& Gonçalves, 2012). However, regardless of the advantages of using an LMS in education, some lecturers are reluctant to use it as a teaching tool (Gautreau, 2011). There are various factors that influence academic staff's decision to use or not use technology for teaching purposes (Eynon, 2005). The purpose of this study is to identify the factors that influence the use or non-use of LMS by academic staff. This paper argues that both internal and external factors need to be considered in order to explain the use or non-use of LMS by academic staff.

Using a qualitative questionnaire, lecturers in a faculty of one university were surveyed regarding their views on the factors that affect their decision to use or not use a LMS. The literature to date shows that internal, external and Universal Theory of Acceptance and Use of Technology (UTAUT) factors are the main factors that affect the use or non-use of LMS.

\subsection{Context and background of the research}

The majority of higher institutions have invested large amounts of money to buy educational tools (Keengwe, Onchwari, \& Wachira, 2008). However, these tools have not always been effectively used (Keengwe et al., 2008), particularly in an African context (Unwin et al., 2010). Kim (2008) suggests that professors are disinclined to use e-learning technologies such as an LMS for instruction in many universities.

A range of studies have been carried out in relation to the factors influencing academic staff's use or non-use of an LMS. External and internal factors have been found to be affect the use or non-use of an LMS by lecturers in higher institutions (Sherbib Asiri, Mahmud, Abu Bakar, \& Ayub, 2012; L. Rogers, 2000). Internal factors include fear, anxiety, no interest in using technology and lack of time to prepare for lectures using technology (Keengwe et al., 2008; Eynon, 2005; Angeli \& Papanastasiou, 2008). According to Elgort (2005) external factors include insufficient technical support, lack of hardware, software and no recognition for using online teaching.

\subsection{Significance of the research}

The review of literature relevant to this study shows different conclusions regarding the factors that affect an individuals' decision regarding use or non-use of an LMS. These different conclusions reveal that there is a need for further research in this area, to identify the factors that affect faculty's use or non-use of technology for teaching and learning purposes. The framework derived as a result of this research can be used to guide further research with regards to the factors to consider when investigating reasons for use and non-use of technologies in educational contexts. 
There may be undiscovered influencing factors for academic staff's adoption and use of LMS, hence future research is required to explore these factors (Coşkunçay \& Özkan, 2013). Al-Busaidi and Al-Shihi (2010) suggest that future qualitative research should be carried out in order to reveal further understanding about these factors. Kim (2008) also states that further research is required. Therefore it is evident that research still needs to be undertaken to identify the factors that affect an individual's decision of whether or not to use technology tools within education, particularly an LMS in this context.

This research seeks to contribute to existing theory by developing a framework that can be used to identify the relationship between the factors that influence academic staff's decision to use or not to use an LMS and moreover understand the influence these factors have on the academic staff's decision. This study also endeavors to contribute to practice through providing results that can be used to comprehend the reason for slow adoption and use of an LMS, the motivators to use and barriers to use of an LMS for teaching and learning purposes.

\subsection{Aims and objectives of the research}

Due to the gap mentioned above, this research addresses the following question:

What are the factors that influence academic staff's decision of use or non-use of a Learning Management System (LMS) in a university context?

The objectives of this paper are:

- to identify the reasons for the use or non-use of an LMS by lecturers,

- to determine the relevance to the context of this research of the factors from the literature regarding the influence on lecturers' decision regarding use or non-use of an LMS,

- to identify any additional factors that are relevant to use or non-use of an LMS.

\section{FACTORS AFFECTING THE USE AND NON-USE OF LMS BY ACADEMIC STAFF}

This literature review is divided into four sections: the UTAUT factors, external factors, internal factors, and the conceptual framework.

\subsection{Unified Theory of Acceptance and Use of Technology (UTAUT) factors}

The UTAUT model illustrates the factors that influence the usage or non-use of technology (Venkatesh, Morris, Davis, \& Davis, 2003). After an assessment of similarities and the differences of eight prominent technology user acceptance models, UTAUT was formulated (Venkatesh et al., 2003). The UTAUT model states that four constructs play a significant role as direct determinants of user acceptance and usage behaviour (Venkatesh et al., 2003). These are: 
performance expectancy, the degree to which an individual believes that using the system will help him or her to attain gains in job performance,

effort expectancy, the ease associated with using a system,

social influence, an individual perception that other important people believe he or she should use the new system, and

facilitating conditions, an individual's belief that an organizational and technical infrastructure exists to support use of the system.

This paper uses these four constructs as concepts within the conceptual framework, which may guide understanding of the reasons for use or non-use. This is a qualitative study that does not aim to test hypotheses. However, UTAUT is well established and, as such, it is likely that the four constructs from UTAUT will help in the analysis of reasons for use and non-use of LMS, whilst the qualitative approach will enable more depth of understanding around the influence of these concepts. Each of the UTAUT factors are subsumed into one of the internal or external factors, as outlined below. The purpose of including UTAUT in this study is to draw parallels in the conceptual framework between existing quantitative and qualitative research.

\subsection{External factors}

External factors refer to obstacles existing in the external environment around use that impede staff's use of an LMS. Sherbib Asiri et al. (2012) argue that external factors can be grouped into three categories; organisational factors (refers to inadequate technical support), technological factors (limited access to useful, relevant, and appropriate hardware and software) and social factors (the degree to which peers support or discourage the user to use technology). Organisational factors refer to technical support in the form of user services or technical specialists who assist staff in the use of an LMS (L. Rogers, 2000). Organisational and technological factors are considered as in line with the facilitating conditions of the UTAUT model and social factors are considered as in line with the social influence construct of the UTAUT model.

\subsubsection{Organisational factors}

Providing instructors with technical support is essential to their acceptance (Al-Busaidi \& Al-Shihi, 2010). In a study by Afshari, Bakar, Luan, Samah, and Fooi (2009), it was discovered that faculty members resisted the use of computers as they did not know how to access help when needed. Therefore, lack of technical support may be stressful for faculty, which may affect their willingness to use the LMS.

Faculty training also affects the integration of LMS into Higher Education (Unwin et al., 2010; L. Rogers, 2000). Teachers need to be given opportunities to practice using technology so that they can see ways to integrate the technology into their teaching (Afshari et al., 2009). Academic staff who are trained are more likely to use the technology than those who are not (Sherbib Asiri et al., 
2012). Adding to this, Buabeng-Andoh (2012) states that training promotes confidence in technology usage. Hence, inadequate training is one of the reasons that faculty members may not use an LMS. Lack of technical support, training and administrative support affects faculty's acceptance and use of technology in education (Teo, 2009).

\subsubsection{Technical factors}

Lack of reliability, performance and timely support could prevent academic staff from using technology (Nanayakkara, 2007). Panda and Mishra (2007) state that lack of computers and technical problems result in barriers in using technology. Hence effective adoption and use of technology in education seems to depend partly on the availability and accessibility of technology resources and lack of technical problems.

The quality of a LMS is of high importance to faculty's decision. System quality includes characteristics of a system such as reliability, accessibility, functionality, interactivity and response time (Pituch \& Lee, 2006). Information quality also plays a role in faculty's decision to use or not use a LMS (Al-Busaidi and Al-Shihi, 2010). Information quality refers to the perception of the output produced by the system, including aspects of accuracy, relevance, timeliness, sufficiency, completeness, understandability and accessibility (Al-Busaidi \& Al-Shihi, 2010). Lwoga (2014) found that both system quality and information quality were significant factors affecting students' perception of usefulness of an LMS, and one would expect that the same would hold true for lecturers' perceptions. 'Perceived usefulness' (or performance expectancy) is an internal factor that is expected to affect use or non-use of an LMS, as discussed below.

\subsubsection{Social factors}

This factor refers to the support or discouragement of peers. This concept is combined with the concept of Social Influence from UTAUT. Frank, Zhao, and Borman (2004) demonstrate how social pressure within an existing social structure (such as a school or university) influences use, suggesting that social pressure is likely to flow from those with more expertise to those with less expertise. They also found that "when teachers perceive that there is a high value in using computers, social pressure may be unnecessary" (Frank et al., 2004, p. 161).

\subsection{Internal factors}

Internal factors are the combination of factors that relate particularly to individuals, for example competency, anxiety and personal innovativeness.

When academic staff members do not feel they are competent enough to use technology, they tend to decline to integrate technology in their teaching (Sherbib Asiri et al., 2012). Computer competency is the extent to which an individual is able to use a computer to perform a variety of applications to accomplish different tasks (Buabeng-Andoh, 2012). In their study, Panda and Mishra (2007) identify lack of knowledge and skills as an internal barrier that results in reluctance to integrating technology in education. According to Compeau and Higgins (1995), computer self-efficacy plays 
an important part in the lecturers' decision regarding usage or non-usage of an LMS. Computer self-efficacy is "the belief that one has the capability to perform a particular behaviour" (Compeau \& Higgins, 1995, p. 189). The acceptance and use of technology is also affected by experience with technology (Al-Busaidi \& Al-Shihi, 2010). Computer literacy is one of the main conditions for the use of any e-learning technology and lack of computer knowledge leads to computer anxiety (Liu, 2005).

Various studies revealed fear, anxiety and lack of interest as a prohibition for using educational technology tools such as an LMS (Keengwe et al., 2008; Angeli \& Papanastasiou, 2008). This is because when faculty is asked to use an LMS as a teaching tool, they may have to change their current technology (if any) and might also be compelled to change the way they teach their students (Keengwe et al., 2008). Change is a challenge because it requires moving from the known to the unknown, causing resistance and fear among lecturers.

Faculty teaching style also affects the usage or non-use of LMS (Al-Busaidi \& Al-Shihi, 2010; Osika, Johnson, \& Buteau, 2009). Ferguson (2004) asserts that academic staff's decision to use an LMS is influenced by their teaching styles and techniques. Teaching styles are based on the needs, emotions, motives, beliefs and attitude of the faculty (Ferguson, 2004). Some lecturers are not eager to use technology, either because they are computer illiterate or because they firmly believe that traditional methods are superior, others embrace technology in an innovative, 'entrepreneurial' fashion (Hagner, 2000).

Among other factors that play a role in faculty's decision whether or not to use technology is personal innovativeness. In the context of information technology this means a person's tendency to experiment or to adopt new information technologies independently of others. According to Al-Busaidi and Al-Shihi (2010), innovative people are more likely to realise the usefulness and ease of use of technology than non-innovative people.

A study was conducted by Eynon (2005), involving a focus group discussion with faculty members in tertiary institutions that use ICTs for teaching their students. An issue for most participants was lack of time to prepare for lecturers using technology. In a similar study, Butler and Sellbom (2002) state that the concern showed by faculty was the time it takes to learn how to use new technology. Assenting to this, Nanayakkara (2007) states that educators point out lack of time to design, develop, maintain and support online classes as a major barrier in using e-learning systems. Much time is needed to build e-skills and create new teaching materials, particularly for inexperienced academic staff (Keengwe et al., 2008).

\subsection{Conceptual framework}

The conceptual framework for this paper integrates internal and external factors with the four constructs from the Unified Theory of Acceptance and Use of Technology model (UTAUT). This framework is relevant for this study because it depicts how users come to accept and use a new technology. In the purpose of this research, the framework will help to identify the factors that influence academics' decisions regarding whether to use or not use LMS. The conceptual framework is shown in Figure 1. Within the framework, external factors include organisational and technological 
factors (which are combined with the facilitating conditions of UTAUT due to the similarity in definition). Social factors are combined with UTAUT's 'social influence' due to the similarity. Performance expectancy and effort expectancy are considered internal factors as they relate to individuals rather than the external environment. Behavioural intention (BI), from UTAUT, refers to "the individual's intention to perform a given behaviour" (Ajzen, 1991, p. 181). Actual use cannot be measured without direct observation of use, or metrics for measuring use. In this paper, BI is used as a proxy for use as Venkatesh et al. (2003) state that behavioural intention has a direct effect on use behaviour.

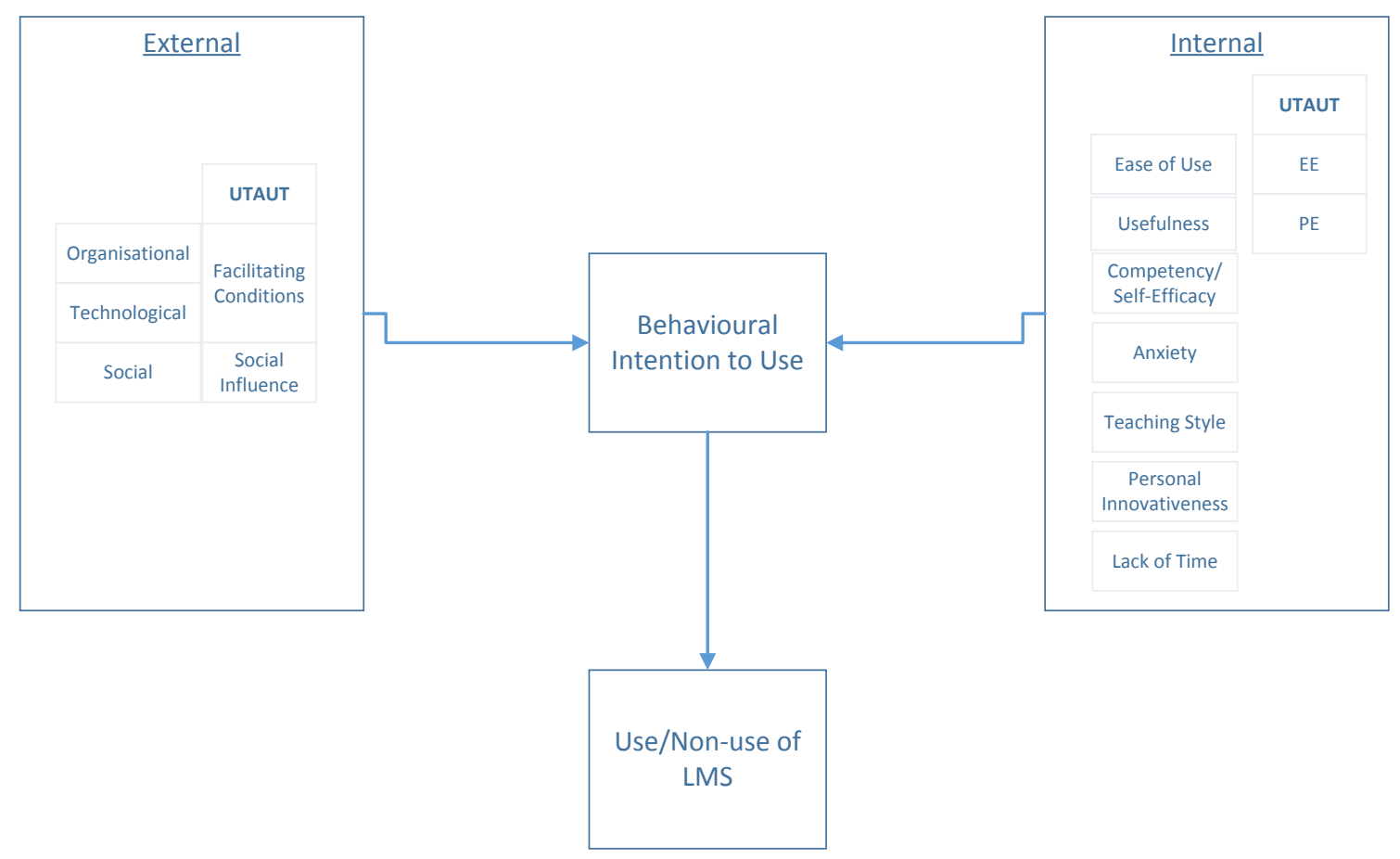

Figure 1: LMS use conceptual framework

\section{RESEARCH METHODOLOGY}

This study was carried out in one faculty of a leading South African university. The purpose of this paper is to identify how lecturers reach the decision regarding usage or non-usage of an LMS and the factors influencing lecturers' decision to use or not use an LMS. This paper provides an in-depth understanding as to why academic staff use or do not use the LMS.

\subsection{Research design}

This paper follows the interpretive research paradigm and uses a qualitative approach. Qualitative studies focus on peoples' lived experiences, perceptions, assumptions and judgements (Van Manen, 
1977). This approach seeks to understand the participants' viewpoints whilst acknowledging the complexity of measuring human behaviour because of the variety of factors that encompass it which are not always observable (Collis \& Hussey, 2003). The research design involves an explanatory case study of the use of a single LMS amongst academics in one faculty. Yin (2009) states that the case study method allows the researcher to capture real-life events holistically and meaningfully. The use of a case study in this research was influenced by the importance of the context in the understanding of individuals' use and non-use of technologies. A case study provides the opportunity to ask incisive questions, to comprehend the phenomenon being explored, and benefit from the richness of the case investigated (Gable, 1994). The purpose of this research was to obtain an in-depth knowledge of the factors that inhibit or motivate academic staff to use or not use an LMS, hence the qualitative method was appropriate in this case.

\subsection{Data collection process}

This study made make use of a self-administered questionnaire to gather data. The benefit of using a questionnaire in this study was because of its ability to gather wide range of information in comparison to interviews. Akbayrak (2000) states that interviews have a shortfall of being more biased than questionnaires. The interviewer may give a hint of opinion or expectations, e.g. by the tone of their voice, the way the interviewer may read questions, or by pausing at certain points, the interviewer may unconsciously influence the respondent. The interviewer may show surprise or boredom and in this way unconsciously communicate their own attitudes and expectations from the respondent (Oppenheim, 1992). As such, a questionnaire was considered more appropriate.

This study made use of a questionnaire with open and closed-ended questions. This was because this study aimed to identify the perspectives, feelings and ideas of individuals about the factors influencing their use or non-use of LMS (qualitative). However, descriptive statistics were used to analyse the percentage of people who share similar or differing experiences or opinions of this subject (quantitative) in order to support the qualitative insights. The questionnaire was devised based on the concepts from the conceptual frameowrk.

The first part of the questionnaire comprised of open ended questions where respondents were asked to write their opinions, plus binary yes/no questions, most of which were followed up by an open ended question so that the participant could elaborate the reasons for their answer. The second part of the survey comprised of demographic information, including closed questions where respondents were asked to tick any boxes that were applicable to them ${ }^{1}$. The questionnaire took between 20 to 25 minutes to complete. The population of this study was both male and female lecturers. This research followed a convenience sampling method. Questionnaires were distributed to lecturers who agreed to take part in the study from the faculty. Questionnaires were left with the lecturers to complete them in their own time of convenience as this would help the respondents to take their time and think clearly before they answered any questions.

Before the actual data collection process, a pilot study was carried out amongst five lecturers from different schools of the faculty. Lecturers were asked to state any confusion or misunderstanding

\footnotetext{
${ }^{1}$ See supplement: http://sacj.cs.uct.ac.za/index.php/sacj/rt/suppFiles/459/0
} 
of terms they encountered in the process of the questionnaire completion. Changes were made accordingly.

\subsection{Data analysis process}

The aim of the qualitative analysis process was to assemble or reconstruct the data in a meaningful or comprehensible fashion (Fossey, Harvey, McDermott, \& Davidson, 2002). Both descriptive statistics and coding were employed. Descriptive statistics analysis was used to analyse percentage quantitative data. This was carried out through manually entering quantitative data into Microsoft Excel and calculating percentage responses to binary questions and assigning consecutive numbers to categorical responses. Qualitative data, obtained from the open-ended questions, was analysed through thematic analysis, which involves categorising the responses into themes and sub-codes (Akbayrak, 2000). Coding involved labelling segments of data to identify themes (Fossey et al., 2002) and sub-codes were developed to aid understanding of each theme. This research followed a partially deductive approach to data analysis, involving use of themes from the conceptual framework to categorise the data. Themes which were already established though existing theory were applied to the data. Analysis also remained open to new themes that emerged from the data, and as such followed Miles and Huberman (1994)'s 'middle-range' approach, falling between purely deductive and purely inductive analysis. Following this, data related to more than one theme was considered in order to uncover patterns and relationships between themes.

\section{FINDINGS}

\subsection{Case background and demographics}

The participants of this study consisted of lecturers from one business focussed faculty of a South African university. The university makes use of an LMS for the purposes of learning and teaching. The LMS used by the institution is commonly known and referred to by the lecturers as 'Sakai'. The university formally introduced e-learning in 2002 and moved to the current LMS in 2012 which offers university wide LMS functionality for all students and staff and is available both on and off campus and on mobile devices. Sakai is used by lecturers for communication with the students including announcements, loading course material which includes quizzes and practice material for the course. Additionally, Sakai is used for marking quizzes and multiple choice questions, to retrieve students' assignments and to verify plagiarism on students' assignments. Thirty two responses were received from the participants. Of these participants, 50\% were male and 50\% were female, $29 \%$ of these individuals were 30 years of age or under, while $59 \%$ were from $31-45$ years and $12 \%$ were 46 years of age or above.

From the data collected, $88 \%$ of the lecturers were full time lecturers whereas $12 \%$ were part time, $63 \%$ of them teach both undergraduates and postgraduate whereas $37 \%$ only teach postgraduate. With regards to lecturing experience, 35\% of the lecturers have an experience of 4 years or less as being lecturers, another 35\% for 5-8 years, 15\% have been lecturing for 9-12 years whilst 15\% have 
lectured for 13 years or more. Further, it was found that there were no lecturers that had never used an LMS before.

This section discusses the findings from data analysis and the relationships found between the factors and the emerging themes. Discussed below are the factors classified under their major themes. The numbers in brackets at the end of quotes show the reference number of the questionnaire from which the quotation was taken.

\subsection{External factors}

\subsubsection{Organisational factors}

As mentioned above, due to the similarity of organisational factors and the organisational aspects of UTAUT's facilitating conditions, these were combined for the purposes of this study. Organisational support refers to technical support in the form of user services or media specialists who assist staff in using and maintaining different technologies, and to the provision of training.

Through analysis it was evident that there was a high rate of non-trained lecturers and if trained, lecturers are undertrained. $56.3 \%$ of lecturers stated that they received training whilst $43.8 \%$ said they were never trained. Of the lecturers that received training $34.4 \%$ stated that the training was adequate whereas $25 \%$ of them highlighted that the training was not enough. Among the various reasons why lecturers felt training was inadequate was due to the issue of the limited time allocated for the training session:

Informal training, maximum 30 minutes. Not enough time. (22)

Training was 2 hours. I mostly learnt how to use LMS by trial-and-error. (20)

Lecturers felt the training was "too short" (13) because there were few training sessions that took place during the year. According to the lecturers it would be acceptable if this amount of time was "just for an introduction" (31) to the LMS, however because there were no further training sessions they deemed the allocated time and sessions as inadequate.

From analysis, this research has discovered that timing for training is important.

Training should be done at the beginning of each semester. (1)

Inadequate training also resulted from the complexity of the LMS which may have needed a large amount of time to learn. Lecturers highlighted that the LMS has many applications and due to this, there is a need for regular training for more advanced features of the LMS.

When we were introduced to Sakai it was difficult to see how it works together. You really have to sit with it and actually work with it to learn. (7)

However despite the concern of inadequate training, one lecturer stressed the lack of time they have as lecturers. 
More training is definitely needed as most of us are self-taught. However time is a problem as most of our time is spent on doing research and preparing for lecturers. (3)

However, some lectures felt that the training "was detailed" (32) and were able to gain sufficient knowledge, as a result they are able to use the LMS for teaching purposes because of the training that they received.

It helped me to effectively use available facilities in class and also for administrative purposes. (24)

The assistants for Sakai ran a demonstration which was helpful. (8)

One of the lecturers mentioned that she never received training because by the time she started in the position, training had passed already. Some lecturers stated that they never received training at all. Therefore these alike had to learn how to use an LMS by themselves through trial and error (continuous use or practice). Lecturers taught themselves using online tutorials, and their background knowledge and experience of computers was also an advantage in this learning process.

My experience has made it possible for me to figure things out for myself. (2)

Additionally lecturers mentioned that they received assistance from Information Technology (IT) technicians whenever they encountered difficulties with the system.

I have received assistance from [tech support] where necessary. (11)

Whenever I have questions [tech support] is available to help me. (6)

However in the course of field notes, it was found that lecturers believe technical support is not the replacement of training - although technical support is available, training should still be conducted. Lecturers stated they do not regard aid from IT technicians as training. This is because they had the burden to make an appointment with the technician and the technician would assist them by specifically answering their questions rather than teach them how the entire system works.

Literature suggests that with technical support made available, lecturers are influenced to use an LMS and they are confident about where to go to when they face challenges with the system. When asked for their opinion regarding the availability of technical specialists in the university, 75\% stated technical support is in place in the university, whereas $25 \%$ said there is no technical support.

\subsubsection{Technological factors}

As mentioned earlier, because of the similarity in the definition of quality, technological factors and the technical aspects of UTAUT's facilitating conditions, these were combined together for the purpose of this study. Technological factors include the availability of hardware and software in addition to quality of the functionality and condition of the infrastructure. To answer this, lecturers were asked if they have the hardware and software necessary to use an LMS and their opinions on the quality of the current LMS. $90.6 \%$ of lecturers agreed that they had the necessary hardware and software to use an LMS whilst 9.4\% said they do not. However it was found that while the lecturers may have the necessary resources, the students may not. 
There is a lack of work stations for all the students on campus. (31)

Lecturers regarded the LMS quality as "good" (32) and "highly acceptable" (3). Reasons being its "reliable" (17), "adequately meets lecturers' needs" (28), "easy to fix errors and always accessible" (5). Further it was discovered that lecturers regard the LMS of good quality because it's "easy to use" $(9,5,29)$, therefore it was concluded that there is a relationship between effort expectancy (ease of use) and quality.

Although the majority of lecturers believed the LMS was of good quality, they also believed it had a number of shortfalls and there was still room for improvement of this tool. These shortfalls included the LMS being "unreliable off campus" (31), "lecturers have to setup courses" (18). As an improvement of the LMS, lecturers desired "to be able to incorporate feedback through applications such as clickers and smart phones to enhance interactive learning" (23) between them and the students.

Interestingly it was seen under the quality theme that lecturers are unclear about their students' needs. This is evident in the following passage:

Seems good and user friendly. Unsure as to how relevant students see it as. (2)

Under this theme training was brought up once again. Lecturers highlighted that "Sakai is ok but more training could be given to new users" (12). One can conclude regardless of how good the quality of the system is, training is very important to lecturers.

\subsubsection{Social factors}

Social support refers to the extent which peers support or discourage the user to use technology. For the purpose of this study it was combined with UTAUT's social influence which refers to one's perception that other important people believe he or she should make use of the system. Lecturers were asked if the attitude or use of an LMS by their colleagues affected them using it themselves and if they were able to ask for advice from their colleagues about the LMS. $21.9 \%$ said they were influenced by their colleagues whilst $78.1 \%$ said they were not influenced by their colleagues. Of those who were influenced, it was found that many are influenced by their colleagues' use of an LMS ('I use it because others are using it') rather than their attitude toward an LMS.

Knowing that others use an LMS means there is a network of individuals who can assist me if I need it. (5)

Concurring with this, others stated "discussions with colleagues make you want to use an LMS as well" (19). However, it was also evident that lecturers are not always influenced by social factors.

One man's meat is another man's poison. I don't care much about what other people's attitude towards an LMS [is]. (1)

And some lecturers are negative about whether they can ask for advice from their colleagues when using an LMS. 
They are just as clueless (22), you end up showing them how to do things. (26)

Apart from the lack of knowledge that their colleagues have, lecturers also mentioned that they do not ask for advice because they "know how to use it" (1) by themselves therefore they see no need to consult others. These negative responses help to explain why $78 \%$ said they were not influenced by their colleagues.

\subsection{Internal factors}

\subsubsection{Lack of time}

As part of data collection, lecturers were asked if they have time to use an LMS and whether they have time to learn how to use an LMS outside training sessions. This is because the literature search found that lecturers do not have time to learn how to use an LMS nor actually use it. In this research, 90.4\% stated they have time to use an LMS while 9.6\% said they do not have the time to use an LMS. Furthermore, $78.1 \%$ stated that they have the time to learn how to use an LMS whereas $21.9 \%$ stated that they do not have the time to do so.

The majority of the lecturers mentioned they have time to use the LMS because "it saves time" (28). Additionally lecturers mentioned they have time to use an LMS for "uploading files and communicating with students" (11). However the 9.6\% who stated they do not have time to use it had the same reason - it was because they had to setup courses when using it and this process was time consuming.

It needs intensive time to setup. (31)

It takes up a lot of time to set it up. (4)

Of the number that stated they do not have time to learn how to use an LMS, lecturers mentioned the reason being that most of their time is already consumed by research and teaching. Nonetheless as a result of insufficient training, a large amount of their research and lecture preparation time is required to be used for learning how to use an LMS and this in turn has negatively affected their allocated time for research.

All the time I took was time taken away from research and is therefore frowned upon by the university. (26)

According to the lecturers, the university is very strict in requiring lecturers to produce research in the time allocated to them, however it does not take into account that lecturers are forced to use part of this time to educate themselves how to use an LMS.

Some lecturers were frustrated because in the process of learning how to use the LMS, they had to create or set-up courses which, as mentioned earlier, is time consuming.

It wasted my time to set-up. I could have been doing research/lecture preparations in that time. (4) 
Due to lack of training, lecturers highlighted they are compelled to learn how the system works. This is through playing around with the system. This way, lecturers are able to discover how the system works, come across new features that can be useful to them and gain knowledge and skills which will enable them to use the LMS for teaching and learning purposes.

You have to explore how it works "trial-and-error". (8)

Some lecturers use it "on a daily or weekly basis" (32) and this enables them to discover how it works. Whether through practice or daily use of the LMS as part of their job, some lecturers feel they are obliged to spare some of their time to learn how to use an LMS instead of being trained by the University.

I had to spend a lot of my own time to learn how to load quizzes on Sakai. (6)

Although there seemed to be lack of training in place, some lecturers were interested in learning or using more of the system and as a result they did not mind having to use their own personal time for learning an LMS. In this context, lack of interest to learn an LMS was not found to be a relevant factor as literature had suggested, rather, there was a high rate of interest in learning how to use an LMS among the lecturers although some indicated they did not have the time. This indicates positive performance expectancy.

I must make the time to learn how to use one as I want to learn how. (14)

I made the time to learn so that I could use the tools adequately. (22)

Additionally, lecturers highlighted they do not mind learning how to use an LMS because it is "easy to use" (1). Part of this ease of use was found to be a result of using the LMS only for basic things such as announcements and loading course material and since these do not require a lot of time, these lectures feel they have the time to learn how to use an LMS.

What I do is very simple and it really didn't take much time to learn. (11)

The ease of use was also because lecturers felt the LMS was user friendly, had simple instructions and was easy to navigate through. Thus the learning process does not consume much of their time.

I don't feel it is particularly difficult to work out, the LMS generally has guidelines and hints. (5)

Thus it was discovered ease of use has a relationship with lack of time to learn. Although lecturers have lack of time to learn how to use an LMS, if it is easy to use, lecturers will be motivated to learn how to use it. 


\subsubsection{Effort expectancy}

Effort Expectancy refers to the perceived ease of use of the system. Lecturers were asked whether they perceive the LMS easy or not to use; $84 \%$ stated the LMS was easy to use, $12.5 \%$ said it was not easy whilst one lecturer said he did not know whether it is easy or not. The majority said it is useful due to its ease of use. By this lecturers referred to the system being "user friendly" (30), having a "simple design" (13) and "having a straight forward layout" (29). Lecturers stated they were motivated to use an LMS because it is "very convenient" (29).

A number of lecturers stressed that the LMS is easy to use because it has instructions and guidelines that assist the user to make use the system.

Has guidelines and explanations of what each section, tab, or button does, so it easy to work your way through it. (5)

Function keys help one to figure out what to do. (3)

Effort expectancy was also influenced by the fact that lecturers were able to use the system without facing challenges.

We are able to do any function we need on it. (21)

I find it easy to use and to teach oneself. (12)

However there were also lecturers who felt some features were badly designed, making it difficult for them to use the system for their daily activities as a result, for them an LMS is time consuming rather than easy to use.

Some functions are badly designed for my particular needs and hence time consuming and irritating to use. (31)

Several lecturers, as mentioned earlier, affirmed that they have the knowledge and skills required to use a computer and an LMS, therefore they do not face intense challenges when it comes to making use of an LMS. Therefore this study found a relationship between knowledge and skills (self-efficacy) and effort expectancy.

I have some technical skills, so it is quite straightforward for me. For others it may be difficult. (25)

Additionally "online tutorials are available" (2) to help lecturers familiarise themselves with the system and by making use of these, they feel the LMS becomes easy to use. Effort expectancy was also discovered to be influenced by the experience that the lecturer has.

I have over six years experience using it. (1)

Several lecturers highlighted that they only use the LMS for basic applications such as announcements and uploading course material, thus, because they only use these few features, they find an LMS effortless to use. 
I am able to do the basics and this is all I need at the moment. But it is also quick to upload material and make announcements. (7)

I only use certain functions which are easy. (22)

Through various responses such as "help is a phone call away" (23), it was evident that technical support has an influence in one's conclusion about the ease of use of the system. Seemingly lecturers felt they could use the system and it was easy to use because someone was in place to assist them whenever they experienced difficulty with the system.

There are lots of skills I don't have but experience has taught me where to find assistance when I need to do something. (31)

Again reflecting the importance of training, a few individuals stated that an LMS is easy "if one has been trained on how to use it" (17), furthermore "only if someone had some form of training or explored what it has" (8).

Of those who said an LMS is not easy to use, they stated that when compared to the previous LMS used by the institution, Sakai is more difficult. This is also because lecturers have "to set up courses and load students manually" (4) on the system whereas with the previous system everything was already in place. Lecturers felt that this is a job which should be done by the administrative personnel not them. When asked about the inhibitors that prevent them from using an LMS, lecturers highlighted the issue of creating courses.

\subsubsection{Performance expectancy}

Performance expectancy relates to the perceived usefulness of the LMS. UTAUT suggests that perceived usefulness is a determining factor in one's decision to use an LMS or not. Further it suggests that if an LMS is useful, individuals are bound to use it however if not, they will not use it. In this study lecturers were asked if an LMS is useful for their job and if it in any way makes their job easier.

Lecturers stressed that the major feature about the usefulness of the LMS was in terms of communication purposes. Lecturers mentioned that an LMS enables instant and mass communication with students. This is beneficial especially when there is a large number of students in one class. An LMS also "reduces communication delivery frameworks" (12), this is of great advantage to them because they have busy schedules and they try by all means to be efficient at all times.

I am able to communicate with students whenever necessary and communication is immediate. (11)

Lecturers deemed the LMS as useful because they are able to be at ease that their messages are conveyed to students and they are likely to read them as compared to when they used notice boards for communication purposes and would remain uncertain as to whether or not their messages were communicated to all the students.

[I'm] more confident students read announcements than posts on a notice board. (16) 
It was surprising to discover that some lecturers regard notice boards as "outdated" (14) methods involved in teaching and learning, indicating a preference for a more modern rather than traditional teaching style. This could be because with an LMS, they are able to send updates should any changes occur to their initial announcements, as this was also one of the reasons mentioned in regards as to why the LMS is useful.

To lecturers the LMS saves time, energy and is less stressful. This is because "it is easy and quick to load course material" (19). Several lecturers stressed that the LMS "reduces the number of students queuing outside their offices to ask the same thing over and over again" (23) and it addresses questions that can be "solved via discussion forum" (1). This reduction of physical contact with students in turn enables them to invest the time to their research.

Reduces contact time with students and frees up time for research. (24)

There was a lecturer who appreciated the reduction of physical contact mainly because it was of great benefit to the students rather than to lecturers.

We cannot make personal contact with students (1000 students), so it provides a way for students to get work assessed without prohibiting logistics.

Hence it is safe to conclude that the LMS is deemed useful in this context because it has bridged gaps between lecturers and students, especially lectures dealing with an enormous number of students.

Additionally lecturers believed that the LMS saves their time because it enables "easy dissemination of course material to students" (27), especially those who are of great number in one class and thus "reduce or eliminate the need for paper work" (7). They are no longer compelled to make any printouts for teaching material - "no need to print large amounts of hardcopies to give to students" (19). Furthermore, there is no need to carry printouts to class which through analysis was discovered to be an unpleasant exercise to lecturers:

Carrying materials around and printing can be daunting. (3)

An LMS eliminates lecturers having to worry about students not having access to teaching material. Lectures expressed their appreciation of the usefulness of an LMS by stressing that it makes "information assessable to students without always having to physically come to the office or school" (24) and when students miss a lecture, "they can go on Sakai and get the notes there" (6).

Lecturers also deemed an LMS useful because its availability has made their lives easier by reducing their workload burdens.

It makes my life so much easier. (11)

Several lecturers stated that they use an LMS for quizzes and MCQs, as a result they "don't have the burden of marking as well" (6) and these "are marked by the system and marks populated" (8).

However, some lecturers highlighted that they are de-motivated to use an LMS because it has some shortfalls in repopulating information, requiring them to do some things manually and this procedure to them is an inhibitor because it is time consuming. 
Some students were not added in the list, had to manually add students - time consuming.

(4)

Additionally, it was evident that some limitations of the LMS inhibit its usage. This was found in one of the lecturers' responses who stated:

Need for more space, I cannot load a video. I asked for more space and did not receive any. (22)

The above statement also suggests that unavailability of technical support becomes a de-motivator of an LMS usage.

Furthermore one lecturer stated that the bad functionality of some features in the current LMS can result in one being prevented to use the LMS.

I want a good maths editor. The one on Sakai is terrible. (31)

According to literature, as discussed above, lecturers are more likely to use an LMS if it meets the needs of their students. To test this previous finding, this study saw fit to include a question about meeting student's needs under the performance expectancy theme. When asked if the LMS meets their students' needs, $28.1 \%$ highlighted they were uncertain whether their needs were met or not. Whilst 9.4\% stated that the LMS does not meet the needs of their students, they did not articulate as to how the LMS falls short in meeting the students' needs. Whereas $62.5 \%$ agreed that the LMS meets the needs of the students. To justify their opinion lecturers mentioned reasons such as students "are able to follow teaching without having to take down notes" (3), they "have easier access to course material" (13) and they "benefit from instant communication" (18). Nevertheless, although many lecturers agreed in that the LMS meets the needs of their students, one respondent stated "however this still needs to be evaluated" (2).

\subsubsection{Teaching style}

It was found that the majority of lecturers stated an LMS is useful, very few preferred traditional methods of teaching. When asked whether they preferred a traditional teaching style, $15.6 \%$ said yes, however, $81.3 \%$ said no. The $15.6 \%$ gave the following responses and this suggests that there is likely to be resistance to change if traditional materials cannot be used.

There is still need for traditional material. (17)

I prefer a combination. (31)

\subsubsection{Competency}

All (100\%) of the lecturers perceived that they have computer self-efficacy - the ability to apply computer skills to accomplish tasks - and 96.9\% stated they have the knowledge and skills required to use an LMS. 
Related to competency was the emerging issue of practice. It was discovered that practice influences the use of an LMS - individuals use an LMS as a result of practice. Moreover as mentioned earlier, one of the lecturers also mentioned that through practise they are able to gain computer skills.

As I use it more and more I pick up new features. (10)

\subsubsection{Personal innovativeness}

With regards to personal innovativeness $96 \%$ of lecturers stressed that they use an LMS although they are not required to do so and some of the reasons being they love technology and love finding new discoveries. Some lecturers stated that they love computers and learning to use them is part of their "hobby" (12). Thus personal innovativeness encourages the use of an LMS and motivates lecturers to make time to learn how to use an LMS, although obliged to make time, to them it is not a constraint.

I am a fan of ICTs and LMSs. (12)

I like playing with computers, so this is not a problem for me. (9)

\subsubsection{Fear and anxiety}

Fear and anxiety were not found to be particularly relevant in this context. $87.5 \%$ of lecturers said they were neither anxious nor feared to use an LMS, while $12.5 \%$ stated that they feared to use it. However of the $12.5 \%$ that said it feared to use it, only $6.2 \%$ responded and gave reasons why this is so. One of the reasons happened to be the unavailability or lack of training. This is manifest in the quote below:

Formal training needs to be given. (17)

As seen in the above sections, training was of great importance in this context. Training appeared several times in the discussion of other themes, showing that there is relationship between it and other themes.

The majority of lecturers, as mentioned earlier, highlighted that they have the essential knowledge and skills needed to use an LMS and they all have computer self-efficacy. Thus this explains why fear and anxiety are not particularly relevant in this context. Indifference also does not appear to be present in this context, due to the high performance expectancy.

\subsubsection{Intention to use}

Lecturers were asked if they intend to continue using the LMS; $100 \%$ of them stated they still use an LMS as frequently as when they began using it and $100 \%$ of them stated they intend to continue using it. This was mainly because of the benefits of the LMS. Lecturers mentioned their intention for continuous use was based on the following advantages.

All the lecturers stated they will continue to use it because it is a very helpful communication medium. 
It provides a good communication platform. (25)

Reliability of communication. (5)

The LMS is also helpful to students in terms of accessing notes, class preparation and self-studying.

Uploading material ahead of class so that students can prepare for class. (15)

Allows more practical examples for student self-teaching and practise. (30)

Lecturers also mentioned their motivation for continuous of an LMS is because "it saves time" (27), "eliminates the need for paper handouts" (26) and as lecturers they are able to "gain computer skills while doing assessments on Sakai" (8).

Furthermore lecturers intend to continually use the LMS because through its usage they are "able to interact with students easily" (17), the LMS is also "convenient" (19) and makes it "easy to post information" (22).

\subsection{Former usage and practices}

This is a new emerging theme that was found during the analysis process. Former usage refers to the use of something mainly because it is better than what was there previously. It was evident in this context that lecturers were influenced to use the current LMS because it was better than the previous ones used by the institution or other online options available. The following quotes concur with the above statement:

[Sakai] is more usable than [the previous system]. [The previous system] is very un-user friendly. (11)

Sakai is much better than Moodle in terms of reliability. (7)

In some departments, although there is one lecturer responsible for the course, it was discovered that some lecturers do not interact with the system by themselves but assign administrators to handle any duties in relation to the LMS. However, this according to the lecturers was not due to lack of knowledge or skills on how to use an LMS but it was due to previous working experience and established course culture practises. One respondent mentioned his previous working experience involved having a personal assistant to take care of the administrative work and this is still his preference. Therefore the department administrator plays the role of being his personal assistant, doing all the administration work through the LMS on his behalf.

Another respondent stated that they (colleagues and himself) assign the work to the administrator because this is the way they found things being done when they began to teach their courses. The culture involved the administrator doing all the LMS related duties and hence they adapted to the existing culture. This implies that the pre-existing culture (practices) affects the way LMS are used in different contexts. 


\subsection{Revised conceptual framework}

Figure 2 is the revised framework resulting from the findings. Contextual has been added to external factors based on the importance of former usage and former practices, and those factors that were considered less relevant are indicated in italics.

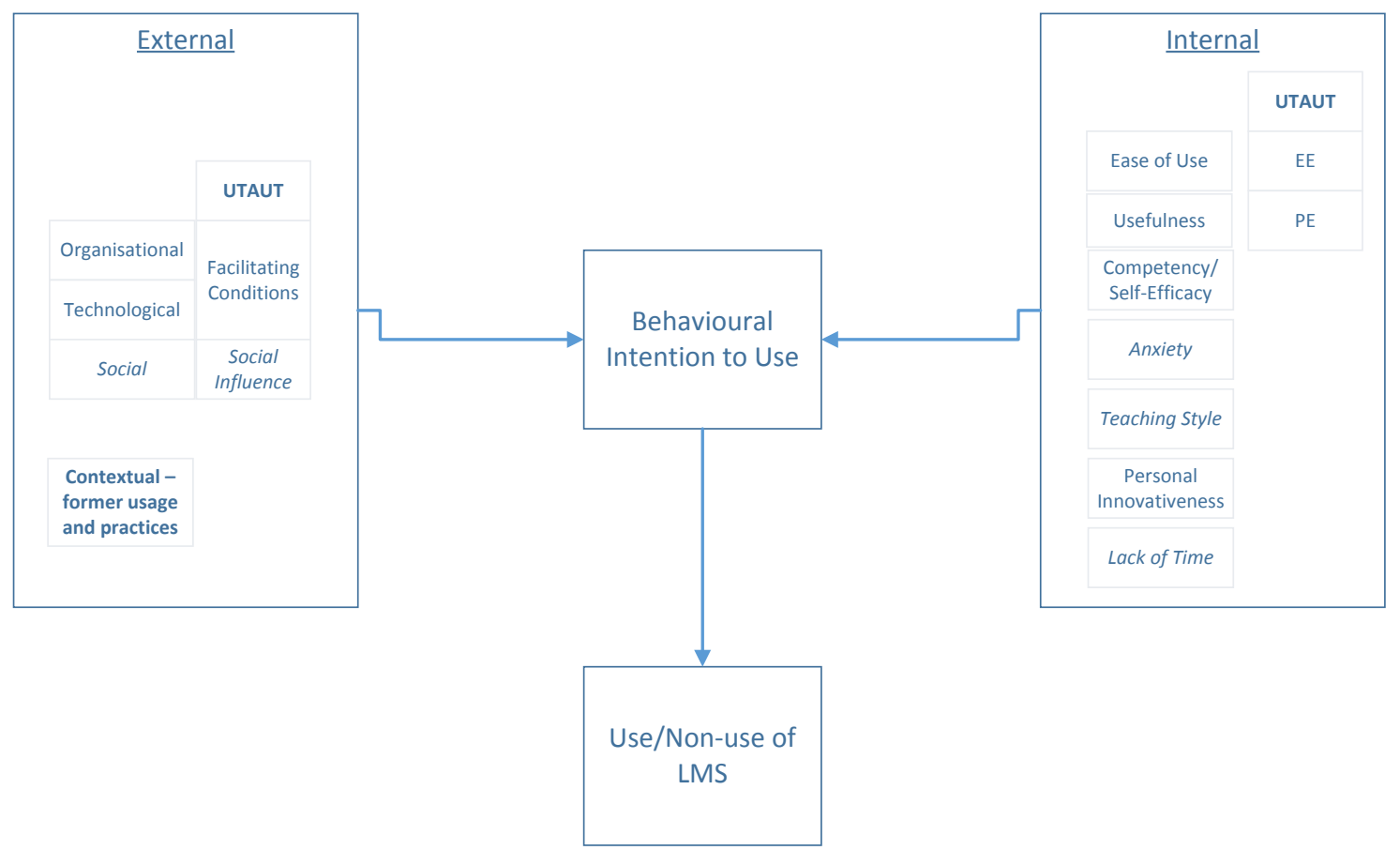

Figure 2: Revised conceptual framework

\section{DISCUSSION}

The following section discusses the objectives of the research in relation to the findings and the literature. The section addresses the following objectives: to identify the reasons for the use or non-use of an LMS by lecturers; to determine the relevance of the factors from the literature regarding the influence on lecturers' decision regarding use or non-use of an LMS; and to identify any additional factors that are relevant to use or non-use of an LMS.

\subsection{Reasons for use of an LMS}

\subsubsection{Organisational factors}

Technical support The results of this study affirm the previous findings from various studies in literature suggesting that technical support is an influential factor that results in lecturers making 
use of an LMS. It was evident in this context that lecturers gained confidence to use an LMS because people with knowledge about the functionality of the system were available to help them with any problems they face in relation to the system.

Respondents were asked if they thought technical support was accessible to meet their arising challenges in the process of using the system and a majority of lecturers asserted that technical support was within reach to assist them should they incur any difficulties with the system. It was discovered that lecturers were inclined to use an LMS because they were aware of the network of individuals at hand to assist them should they incur challenges while using the system. The results of this study concur with literature in that the accessibility of technical support leads to the use of an LMS. Lack of technical support constitutes one of the principal causes why adoption and usage of eLearning technologies do not succeed (Black et al., 2007).

Training The results of this study show that, as found in the literature, training is a very important aspect in the use of an LMS.

Despite the assertion that training time was too short for learning the extended features of the system, lecturers stated they felt confident to use the LMS to deliver their courses. The training was detailed enough to enable them to gain knowledge on how to use the basic features of the system. Lecturers who attend in service training are more likely to use technology than those who did not receive any training (Al-Alwani \& Soomro, 2009).

It was also found that having knowledge and skills (self-efficacy) about computers is beneficial to an individual, this saves time involved in learning how to use the system. Thus this study discovered there was a relationship between training and knowledge and skills. Training was to be of great importance in this context because the system was still new.

\subsubsection{Technological factors}

This theme sought to find out if lecturers had accessibility to hardware, software and necessary infrastructure to use an LMS. Further the theme explored the standard of quality of the hardware, software and infrastructure. $90 \%$ of the lecturers stated they had the necessary hardware and software to make use of an LMS. Several lecturers highlighted that they were pleased with the quality of the system because among many reasons, it was good and reliable. Due to this they were prompted to use the LMS. Additionally, lecturers regarded the LMS as of good quality because it was easy to use, this finding resulted in the relationship between quality and effort expectancy. As mentioned earlier, training was found to have a relationship with several other themes and quality was one of these themes. According to lecturers, although the quality was satisfactory, training was needed for optimal use of the LMS.

\subsubsection{Effort expectancy}

This theme relates to the user's opinion on how easy the system is to use. From the empirical findings, ease of use was very high amongst the respondents. The use of instructions, simple layout and guidelines proved to play a part in lecturers' definition of a system that is easy to use and the 
availability of these features resulted in impacting the reason why many were prompted to use an LMS. Effort expectancy was also influenced by the knowledge and computer self-efficacy and experience possessed by the lecturers. A number of lecturers indicated that they have experience either in working with computers in general or with using an LMS. It was evident that the availability of experience leads one to deem an LMS as easy to use, thus a relationship between effort expectancy and experience was found to exist.

Additionally, lecturers had access to online tutorials to assist them to learn how the system works. Furthermore this study discovered that there was a relationship between effort expectancy and technical support. Technical support refers to the IT specialists provided by the university to offer lecturers help with using the system. Several lecturers highlighted that an LMS was easy to use due to the availability of technical support in place to assist them whenever they experienced difficulties with the system. Therefore, in turn, ease of use motivated them to use an LMS for teaching and learning purposes.

\subsubsection{Performance expectancy}

This theme describes the user's perception about the usefulness of an LMS. Empirical findings showed that lecturers deemed the LMS useful because it provided an instant, reliable and easy means of communication between them and the students. Technology has the ability to provide effective means of communication between lecturers and students (Bingimlas, 2005) and between students (Abu-Al-Aish \& Love, 2013).

Furthermore an LMS was found to reduce the need for print outs which happened to be a frustrating experience for lecturers especially when it came to carrying them and having a class with a large number of students. Thus, the LMS enables ease of access to course material and notes required by the students.

Additionally, the LMS lessens the physical contact between lecturers and students, allowing lecturers to focus more on their research rather than attending to students' needs individually which can be addressed through an LMS. Due to these benefits, lecturers were influenced to use the LMS. However it was also noticed that resistance to change is likely to exist if traditional methods of teaching may come to an end. According to Bingimlas (2005), resistance to change forms part of the barriers of incorporating technology in the learning environment.

\subsubsection{Personal innovativeness}

This refers to an individual being driven by self-motivation to make use of or learn how to use an LMS though not obliged to. A large majority of the lecturers use the LMS even though they are not obliged to do so, and expressed innovativeness to explore using computers, although lack of time to do so and lack of training caused restrictions in this. As a group, the lecturers seemed to be highly innovative in that they chose to use the system, but less so in terms of using extended features. The group was also very positive towards the ease of use (effort expectancy) and usefulness (performance expectancy). This supports the literature that suggests that there is a relationship between innovativeness and perception ease of use and usefulness (Al-Busaidi \& Al-Shihi, 2010). 


\subsubsection{Competency}

It was found that several of the respondents possess a computer related qualification or have previous experience working with an LMS or computer. Therefore their possession of either qualification or experience formed part of the reason that influenced their use of an LMS. Assenting to this, Pelgrum (2001) suggests the integration of technology is dependent largely on academic staff's knowledge and skills, whilst Lee and Lee (2014) suggest that it is teachers' self-efficacy beliefs in their ability to integrate technology into the classroom that has the most important effect on use. Toyama (2015) suggests that without both capability and intention, educational technologies cannot be successful.

Practice refers to the continuous use of an LMS. It was discovered that practice influences the use of an LMS and because of it lecturers are able to gain the necessary skills and knowledge needed to use an LMS.

\subsubsection{Experience}

This refers to the number of years that one has used an LMS. The majority of respondents indicated that they have used an LMS for more than three years. It was evident that experience is a contributing factor to the use of an LMS as respondents mentioned experience as one of their reasons for using an LMS. It was also discovered that experience has a relationship with other factors such as lack of time.

\subsubsection{Former usage}

This theme emerged due to the comparison that lecturers made between the current system and the previous one used by the institution. It was found that lecturers are influenced to use the new LMS because it is better than the previous one.

This is in agreement with what E. Rogers (1995) refers to as 'relative advantage': if an innovation is deemed better and more effective as compared to its similar products, it is expected to be used more.

\subsection{Reasons for non-use of an LMS}

Contrary to expectation from the literature search, there were no examples of complete non-use of the LMS. However, there is evidence of the potential non-use of extended features i.e. inadequate optimisation of the LMS. Thus, the following section discusses the inhibitors and reasons for the non-optimisation of the LMS by academic staff in the institution.

\subsubsection{Effort expectancy}

Although, as mentioned earlier, generally academic staff found the LMS easy to use, it is also true that some regarded the LMS as not easy to use. This is because some of the features were not intuitive, demanding a lot of time to learn.

A few lecturers also highlighted that unlike the previous LMS used by the university, the current one requires them to create courses and add students manually on the course list. Not only is this 
process time consuming but lecturers felt it is too administrative and someone else should be assigned to the duty, not them (based on former practices surrounding the previous system). According to Bower (2001), the use of an LMS is likely to slacken if the new innovation (LMS) is not integrated to the existing culture. Therefore, the reason for unease of use of the LMS facing some lecturers could be a result of the new LMS not being integrated to the existing culture, which in this case is Sakai not being able to create and repopulate courses like the previous system.

\subsubsection{Training (organisational factors)}

A number of lecturers affirmed that they did not receive training and of those that were trained, a high percentage stated training was insufficient, and would have preferred more regular training than the one-off initial training, that may have led to usage of more advanced features. Dube and Scott (2013) also found that lecturers required more regular training for use of the Sakai system at a different university. As a result of absence or insufficient training, lecturers are unable to use some features of the LMS, mostly advanced features. Partial use of the LMS results in the LMS not being optimised by the institution. According to Y., Yildirim, and Yildirim (2009), training is one of the primary barriers in the integration of technology in the learning environment. Assenting to this, Pelgrum (2001) and Balanskat, Blamire, and Kefala (2006) state that training seems to have always been one of the core obstacles among lecturers decision to adopt or use technology.

\subsubsection{Technological factors}

As mentioned earlier, academic staff stated they have the necessary hardware and software to enable them to use an LMS, however these do have their shortfalls leading to lack of optimisation of the LMS. One lecturer stated that the LMS is limited in terms of space to allow her to add videos for her course. She is then compelled to download the videos into a flash disk in order to play them in class and give students the links to access these videos as the LMS falls short to accommodate this feature.

\subsection{Factors not applicable in this context}

\subsubsection{Social factors}

Social support which relates to peer-support was not found to be an influential factor in this context. It was discovered that lecturers are not influenced by their colleagues use or attitude towards an LMS. Furthermore lecturers stated that they would use an LMS regardless of their colleagues' actions or thoughts about the LMS because an LMS makes their lives easier. This may be explained by the findings of Frank et al. (2004). In their study, both high expertise and high utility of the system reduced the influence of social factors. In this case, a high perception of utility is found, plus a high level of competency. 


\subsubsection{Lack of interest}

The results of this study were contrary to the findings suggested by previous studies in the literature. According to literature, academic staff do not use an LMS due to lack of interest. However, this study found that lecturers are interested in an LMS and this interest, amongst many reasons, was seen to be triggered by the convenience brought by the LMS.

\subsubsection{Lack of time}

The results of this theme differ with literature which suggests that lack of time results in non-use of an LMS (Nanayakkara, 2007; Butler \& Sellbom, 2002). Although there were respondents who indicated that they do not have time to learn how to use an LMS, it was discovered that academic staff create both time to learn how and time to use an LMS through practice. Regardless of the impact this has on their other duties, academic staff do not cease to explore an LMS. Among many reasons it was evident that this contradiction was caused by the fact that majority of the academic staff indicated that they have self-efficacy and personal innovativeness. Practice is influenced by personal innovativeness, love for computers and lack of knowledge of the system. Y. et al. (2009) concurs with the findings of this study by stating that lack of time is not an obstacle to the usage of technology.

\subsubsection{Traditional teaching}

As mentioned above, literature suggests that academic staff have different styles of teaching, some prefer traditional methods and some prefer to innovate with technology. In this context both traditional teaching and an absolute reliance on technology for teaching were two shunned extremes. Instead lecturers were happy with the availability of an LMS however, some still believed there is a need for the traditional methods of teaching, thus they prefer both technology and the traditional method.

\subsubsection{Fear and anxiety}

This theme did not apply to this context. It was found that a number of lecturers had previous working experience with an LMS and had skills and knowledge of not only using a computer but an LMS too. Therefore, the availability of these was seen to be the leading reason for the absence of fear or anxiety in the lives of individuals.

\section{CONCLUSION}

In discovering the literature highlighting the underuse of LMSs in tertiary institutions, regardless of their benefits and large amount of money invested in them, this research sought to explore what factors impact the use or non-use of an LMS. This research was lecturer-centric, thus only lecturers formed part as the participants of this research. This research aimed to determine the influential 
factors to academic staffs' decision regarding whether or not to use an LMS. Thus this research sought to answer the following research question:

What are the factors that influence faculty's use of or non-use of a Learning Management System (LMS) in a university context?

This section will discuss how the research question was answered through the objectives stated in the introduction. Further it will discuss the research contributions, limitations and future research identified by this study.

\subsection{Research objectives}

\subsubsection{Identify the reasons why academic staff use an LMS}

The main findings of this study showed that there is high use of an LMS by the majority of academic staff, contrary to previous studies on LMS usage, particularly in an African context. Training was found to be a major issue in this context, mainly because the LMS was new in the institution and training also had a relationship with most of the other themes.

The majority of the lecturers were found to have computer self-efficacy because they held a computer related qualification or had years of experience with using an LMS. Thus, this knowledge and skills influenced their use of an LMS. Moreover lecturers regarded the LMS easy to use, useful and of good quality. The availability of technical support to assist the lecturers when faced with difficulties was also found to contribute to the reasons why lecturers decide to use an LMS. Moreover contrary to literature, lecturers stated their usage of an LMS is influenced by their interest in learning how to use the tool.

\subsubsection{Identify the reasons why academic staff do not use an LMS}

In this study it was found that there is lack of optimisation of the LMS through use of advanced features rather than complete non-use. The lack of effective use of the LMS was due to inadequate training and limitations of the LMS such as insufficient space. Lecturers also mentioned they lacked time to learn how to use the LMS. Furthermore lack of optimisation was due to badly designed features of the LMS which did not meet the needs of lecturers.

\subsubsection{Determine whether existing factors are relevant in the context of this study}

The majority of the factors suggested by literature were discovered to be applicable to this context. Among many these include performance and effort expectancy, technical support, personal innovativeness and experience.

However, some factors such as fear and anxiety were not applicable to this context. Social influence, lack of time to learn and lack of interest were also found not to apply to this context. This study discovered that most of these factors did not apply due to the knowledge, skills and personal motivation that the majority of lectures have. 


\subsubsection{Discover if there are any additional factors in this context}

In the course of analysis it was discovered that lecturers' use of an LMS is affected by practice, lecturers are more likely to use an LMS if they continually practise using it. Practice was also found to provide lectures with skills to use an LMS. This was subsumed under the competency theme.

The core emerging theme was that of former use and practices/culture. Former usage refers to using something because it is better than what was there previously. It was evident lecturers based their use of an LMS on comparison with the former LMS which the University used; they use the current LMS because it is better than the former LMS. It was also found that pre-existing practices in the context of some academics influenced the way the LMS was used.

\subsection{Contributions of the study}

This section will discuss the contribution made by this study to theory and practice and discuss why these are important.

\subsubsection{Contribution to theory}

This study contributed to theory by providing an in-depth explanation as to why some existing factors influence the use or non-use of an LMS. Additionally, a contribution was made by identifying the factors relevant and not relevant to this context and providing the reasons why this may be so. Furthermore, this study identified that there is a need for usage studies to consider the pre-existing practices and previous technologies used in order to understand the way in which systems are used.

Although respondents stressed the issue of inadequate training it was found that there is a low rate of effort expectancy amongst the lecturers. Lecturers felt that the LMS is easy to use whilst they stated training was needed. Furthermore it was discovered a majority of the lecturers had experience, skills and knowledge on the use of an LMS yet insisted on training.

This research discovered that there was a contradiction in the responses from respondents. Therefore one can conclude it was uncertain as to whether the training was demanded because of principle, when a system is new people ought to be trained, or because there was an actual need for the training. However, it was evident that level of usage differs from person to person, leading to consistent reports of low effort expectancy. Some lecturers only use basic functions of the system and due to this an LMS is easy for them to use. Whereas some lecturers use many applications on the LMS but have previous experience with using an LMS and as a result it is easy for them to use it. Hence the demand for training could be because lecturers want to be trained to use advanced features of the LMS.

Existing literature suggests that lecturers have different teaching styles, claiming that lecturers are either traditionalists or innovative. However, contrary to literature this study discovered that lecturers can prefer both traditional and technological rather than one over the other.

The revised theoretical framework devised from the results of this research prodive a guide for future research into reasons for use and non-use of technologies in an educational context. 
Furthermore this study was conducted in a South African context and provided results from a South African perspective, showing that not all contexts are the same.

\subsubsection{Contribution to practice}

This study also contributed to practice as the results can be used to understand the use, non- use and reasons for non-optimisation of an LMS amongst lecturers. These results can also be of help in comprehending the reasons for slow adoption and acceptance of an LMS by academic staff.

This study discovered it is important to provide continuous training sessions for academic staff, especially when the system is new as seen in this context. Training should be allocated a reasonable amount of time, an hour or more. However through observance it was evident that time spent on training whether 30 minutes or an hour would not be a problem to lecturers as long as there are multiple training sessions, but seeing that there was no ongoing training, training was deemed inadequate.

For optimal usage of the system this study found that technological factors of the LMS need to be improved. This includes increasing the space on the education tool and providing applications that meet the needs of the lecturers such as twitter integration and an advanced mathematics editor, as they had stated that one of the inhibitors in making use of an LMS is their needs not being met by the features of the LMS.

The research also discovered that some lecturers feel they are doing administrators' work by creating courses and adding students manually on the system. Therefore, to ensure optimised use of the LMS, the university should provide clear guidelines for whose role this is, or improve the LMS to cater for this function automatically.

\subsection{Limitations to the study}

This study used convenience sampling. In choosing this approach, certain individuals who had equal opportunity to be sampled were left out during the selection process while other individuals were overrepresented in the sample. The majority of respondents were between 25-45 years and only $12.5 \%$ were above 45 years. Due to this, the younger age group was overrepresented and the results of this study could have been different if the was a balance between the two parties.

Moreover this study was carried out only in one institution and only in a business faculty, as such the respondents may be more comfortable with technology than in some other university faculties.

\subsection{Recommendations and future study}

The findings of this study may be only relevant to a context where the system is new. Hence there is a need to understand whether factors affecting the use of an LMS differ depending on how long the system has be in existence in a particular institution. Future research is needed to explore if there is any difference in influential factors of using an LMS when the system is new or has been in use for a long period of time. 
As mentioned earlier, this study discovered that lecturers do not necessarily know the needs of their students. Therefore a study can be undertaken to explore the needs of the students and inform lecturers about students' needs in relation to LMS.

Future research can use the revised framework as a guide for understanding use and non-use of technologies in educational contexts.

\subsection{Conclusion}

The provision of training is of great importance when the system is new. Training affects other factors such as ease of use and if inadequate, underutilisation of the system can be the result, particularly with regards to more advanced features. There was a high rate of LMS usage and overall the majority of lecturers regarded it as a beneficial teaching tool, this was evident in lecturers' frequent use of the system and that all of them intended to continue to use it regardless of its shortfalls. However, more advanced use could be supported through advanced training sessions.

\section{References}

Abu-Al-Aish, A. \& Love, S. (2013). Factors influencing students' acceptance of m-learning: An investigation in higher education. The International Review of Research in Open and Distributed Learning, 14(5), 1-26.

Afshari, M., Bakar, K. A., Luan, W. S., Samah, B. A., \& Fooi, F. S. (2009). Factors affecting teachers' use of information and communication technology. International Journal of Instruction, 2(1), 77-104.

Ajzen, I. (1991). The theory of planned behavior. Organizational behavior and human decision processes, 50(2), 179-211. https://doi.org/10.1016/0749-5978(91)90020-T

Akbayrak, B. (2000). A comparison of two data collecting methods: Interviews and questionnaires. Hacettepe Üniversitesi Ë̈itim Fakültesi Dergisi, 18, 1-10.

Al-Alwani, A. \& Soomro, S. (2009). Integration of information technology in science education at Yanbu, Kingdom of Saudi Arabia. In A. Lazinica \& C. Calafate (Eds.), Technology, education and development (pp. 151-162). InTech.

Angeli, C. \& Papanastasiou, C. (2008). Evaluating the use of ICT in education: Psychometric properties of the survey of factors affecting teachers teaching with technology (SFA-T3). Educational Technology and Society, 11(1), 69-86.

Balanskat, A., Blamire, R., \& Kefala, S. (2006). The ICT impact report: A review of studies of ICT impact on schools in Europe. Last accessed 20 Nov 2017. Retrieved from http://www.colccti. colfinder.org/sites/default/files/ict_impact_report_0.pdf

Bingimlas, K. (2005). Barriers to a successful integration of ICT in teaching and learning environments: Of literature. Eurasia Journal of Mathematics, Science and Technology Education, 5(3), 235-245.

Black, E. W., Beck, D., Dawson, K., Jinks, S., \& DiPietro, M. (2007). Considering implementation and use in the adoption of an LMS in online and blended learning environments. TechTrends, 51(2), 35-53. https://doi.org/10.1007/s11528-007-0024-x 
Bower, B. L. (2001). Distance education: Facing the faculty challenge. Online Journal of Distance Learning Administration, 4(2), 1-6.

Buabeng-Andoh, C. (2012). Factors influencing teachers' adoption and integration of information and communication technology into teaching: A review of the literature. International Journal of Education and Development using Information and Communication Technology, 8(1), 136-155.

Al-Busaidi, K. A. \& Al-Shihi, H. (2010). Instructors' acceptance of learning management systems: A theoretical framework. Communications of the IBIMA, 2010. https://doi.org/10.5171/2010. 862128

Butler, D. L. \& Sellbom, M. (2002). Barriers to adopting technology. Educause Quarterly, 2, 22-28.

Cabral, B., Pedro, N., \& Gonçalves, A. (2012). LMS in higher education: Analysis of the effect of a critical factor 'faculty training'.

Collis, J. \& Hussey, R. (2003). Business research: A practical guide for undergraduate and postgraduate students (2nd). Palgrave Macmillan.

Compeau, D. \& Higgins, C. (1995). Computer self-efficacy: Development of a test. MIS Quarterly, 19(2), 189-211.

Coşkunçay, D. F. \& Özkan, S. (2013). A model for instructors' adoption of learning management systems: Empirical validation in higher education context. The Turkish Online Journal of Educational Technology, 12(2), 13-25.

Dube, S. \& Scott, E. (2013). An empirical study on the use of the Sakai Learning Management System (LMS): Case of NUST, Zimbabwe. In Proceedings of the e-Skills for Knowledge Production and Innovation Conference 2014, Cape Town, South Africa (pp. 101-107). https://doi.org/10. 13140/RG.2.1.2589.1048

Elgort, I. (2005). E-learning adoption: Bridging the chasm. In Proceedings of Ascilite 2005 (pp. 181$185)$.

Eynon, R. (2005). The use of the internet in higher education: Academics' experiences of using ICTs for teaching and learning. Aslib proceedings, 57(2), 168-180. https://doi.org/10.5171/ 2010.862128

Ferguson, P. (2004). Faculty beliefs about teaching with technology. In Proceedings of the National Convention of the Association for Educational Communications and Technology, vol. 2 (pp. 155166).

Fossey, E., Harvey, C., McDermott, F., \& Davidson, L. (2002). Understanding and evaluating qualitative research. Australian and New Zealand journal of psychiatry, 36(6), 717-732. https://doi.org/ 10.1046/j.1440-1614.2002.01100.x

Frank, K., Zhao, Y., \& Borman, K. (2004). Social capital and the diffusion of innovations within organizations: The case of computer technology in schools. Sociology of Education, 77(2), 148-171. https://doi.org/10.1177/003804070407700203

Gable, G. (1994). Integrating case study and survey research methods: An example in information systems. European Journal of Information Systems, 3(2), 112-126. https://doi.org/10.1057/ ejis.1994.12

Gautreau, C. (2011). Motivational factors affecting the integration of a learning management system by faculty. The Journal of Educators Online, 8(1). https://doi.org/10.9743/JE0.2011.1.2 
Hagner, P. (2000). Interesting practices and best systems in faculty engagement and support. Final report to the National Learning Infrastructure Initiative (January 25, 2001). Last accessed 8 Dec 2017. Retrieved from https://www.educause.edu/ir/library/pdf/NLI0017.pdf

Keengwe, J., Onchwari, G., \& Wachira, P. (2008). Computer technology integration and student learning: Barriers and promise. Journal of science education and technology, 17(6), 560-565. https://doi.org/10.1007/s10956-008-9123-5

Kim, R. (2008). Factors influencing the acceptance of e-Learning courses for mainstream faculty in higher institutions. International Journal of Instructional Technology and Distance Learning, 5(2), 29-44.

Lee, Y. [Y.] \& Lee, J. (2014). Enhancing pre-service teachers' self-efficacy beliefs for technology integration through lesson planning practice. Computers and Education, 73, 121-128. https: //doi.org/10.1016/j.compedu.2014.01.001

Liu, C. (2005). The attitudes of university teachers to adopt information technology in teaching. Information Technology Journal, 4(4), 445-450. https://doi.org/10.3923/itj.2005.445.450

Lwoga, E. (2014). Critical success factors for adoption of web-based learning management systems in Tanzania. International Journal of Education and Development using Information and Communication Technology, 10(1), 4.

Miles, M. B. \& Huberman, A. M. (1994). Qualitative data analysis: an expanded sourcebook. Sage.

Nanayakkara, C. (2007). A model of user acceptance of learning management systems: A study within tertiary institutions in New Zealand. International Journal of Learning, 13(12),

Oppenheim, A. (1992). Questionnaire design, interviewing and attitude measurement. Pinter.

Osika, E. R., Johnson, R. Y., \& Buteau, R. (2009). Factors influencing faculty use of technology in online instruction: A case study. Online Journal of Distance Learning Administration.

Panda, S. \& Mishra, S. (2007). E-Learning in a mega open university: Faculty attitude, barriers and motivators. Educational Media International, 44(4), 323-328. https://doi.org/10.1080/ 09523980701680854

Pelgrum, W. (2001). Obstacles to the integration of ICT in education: Results from a worldwide educational assessment. Computers and Education, 37(2), 163-178.

Pituch, K. \& Lee, Y. [Y]. (2006). The influence of system characteristics on e-learning use. Computers and Education, 47, 222-244. https://doi.org/10.1016/j.compedu.2004.10.007

Rogers, E. (1995). Diffusion of innovations: Modifications of a model for telecommunications. In Die diffusion von innovationen in der telekommunikation (pp. 25-38). Springer. https: //doi.org/10.1007/978-3-642-79868-9_2

Rogers, L. (2000). Barriers to adopting emerging technologies in education. Journal Of Educational Computing Research, 22(4), 455-472.

Sherbib Asiri, J., Mahmud, R., Abu Bakar, K., \& Ayub, A. (2012). Factors influencing the use of learning management system in Saudi Arabian higher education: A theoretical framework. Higher Education Studies, 2(2), 125-137. https://doi.org/10.5539/hes.v2n2p125

Teo, T. (2009). Modelling technology acceptance in education: A study of pre-service teachers. Computers and Education, 52(2), 302-312. https://doi.org/10.1016/j.compedu.2008.08. 006 
Toyama, K. (2015). Geek heresy: Rescuing social change from the cult of technology. PublicAffairs.

Unwin, T., Kleessen, B., Hollow, D., Williams, J., Oloo, L. M., Alwala, J., . . Muianga, X. (2010). Digital learning management systems in Africa: Myths and realities. Open Learning: The Journal of Open and Distance Learning, 25(1), 5-23. https://doi.org/10.1080/02680510903482033 Van Manen, M. (1977). Linking ways of knowing with ways of being practical. Curriculum Inquiry, 6(3), 205-228.

Venkatesh, V., Morris, M., Davis, G., \& Davis, F. (2003). User acceptance of information technology: Toward a unified view. MIS Quarterly, 27(3), 425-478.

Y., Yildirim, S., \& Yildirim, Z. (2009). Main barriers and possible enablers of ICTs integration into pre-service teacher education programs. Educational technology and society, 12(1), 193-204.

Yin, R. (2009). Case study research: Design and methods. Sage. 